\title{
Material Cost Comparison for Masonry and Framed Partition Walls for Buildings in Uganda
}

\author{
Aloysius Omongin Osele Vanessa Asiimwe Ronald Ekyalimpa* \\ College of Engineering, Art, and Design, School of Built Environment, Makerere University, PO box 7062, \\ Kampala, Uganda
}

\begin{abstract}
In the building construction industry, decisions concerning specifications for the different building components may be made by the client, consultants, contractor, or a combination of these. Choices are usually governed by functionality (strength and safety integrity, durability), aesthetics, cost, material availability, technical know-how, etc. Most of these criteria are easy to quantify except for strength, safety, durability, and cost given that they require rigorous analysis or research. This study set out to determine the cost margin difference that exists between wall types (framed and masonry wall) from a material requirements perspective. This was meant to avail information that can provide decision support to practitioners or clients that need to make a choice between these wall types. Margins for cost differences were computed using a Monte-Carlo simulation-based approach that involved sampling deviates from probability distributions for costs for $1 \mathrm{~m}^{2}$ of framed and masonry walls. These costs were built-up through another Monte-Carlo simulation process that utilized material quantities and unit prices as its inputs. There was transformation work done in this simulation experiment to reconcile material quantity conventions used by vendors and manufacturers with those quantities required to erect $1 \mathrm{~m}^{2}$ of a physical wall.
\end{abstract}

Keywords: Framed wall, Masonry wall, Cost margin, Probability distribution, Monte-Carlo simulation

DOI: $10.7176 / \mathrm{CER} / 12-5-05$

Publication date:May $31^{\text {st }} 2020$

\section{Introduction}

Building infrastructure for residential, commercial, and institutional purposes embed within them walling systems and their associated components and sub-components. These walling systems may be designed to behave as integral structural elements (e.g. shear walls) or as non-structural elements (typically for partitioning floor space). Regardless of their intended purpose, walling systems may be categorized at a high-level as external walls or internal walls. External walls primarily provide a shield from harsh weather, serve a safe shield from falls and various forms of attacks, and contribute to the overall aesthetics of the building. Internal walls on the other hand, primarily serve in partitioning floor space. This partitioning could be for purposes of sound-proofing, creating private spaces, etc. Both wall system categories can be structural or non-structural walls. It is the type of material that the wall is constructed in and the fact that it is intended to resist forces (typically lateral forces), that qualifies a wall as structural. Most structural walls will be constructed in masonry, or reinforced concrete while nonstructural walls can be constructed in masonry, timber framing, or steel framing. Different sheathing materials are used in the framing as part of this type of walling system. Examples of commonly used sheathing materials include foamed or reinforced plastic, gypsum board, timber board, metal, glass, etc. When a walling system is being constructed for structural resistance, the objective is strength while non-structural walls the objective is to optimize (minimize) the weight, construction time, and cost. The strength criteria is achieved through the appropriate selection of materials and appropriate sizing, i.e. the thickness. Non-structural walls should generally be easier to erect and dismantle compared to structural walls which are mostly constructed to be a permanent component of the building.

It is evident that there are different options available to practitioners for the construction of non-structural walling systems, i.e. masonry, framed wall - also referred to as drywall. The framed wall options are also at the disposal of practitioners. Often, those in design and construction have to make decisions on which walling system options to adopt for their building projects. Factors that influence the type of wall to be used include: (1) the material availability at a reasonable cost, (2) the availability of craftsmen capable of using the materials optimally, (3) climate, and (4) the functional requirements of the building (FAO \& INPho, 1988). When the main criteria for deciding the type of non-structural wall to build is hinged about cost, then the decision-maker has to critically look into the components that contribute towards a cost built-up for the walling system. The largest components that are known to contribute towards the capital cost for walling systems are material and labor. Consequently, material and labor cost built-ups for the different viable types of walling systems that could be utilized becomes necessary. In order to build-up such costs, analysts would require material quantities consumed in each unit, labor quantities expended in each unit, and market surveys of unit costs for material and labor. In developed construction industries, material and labor quantities expended per unit of wall type are often summarized in cost estimation repositories such as RSMeans, Cost Data Online, BNI Building News, Design \& Construction Resources, etc. (Nardon, 1995). These metrics are obtained after rigorous benchmarking studies of these activities as they are being carried out on 
site. Such benchmarks are often context-specific and hence cannot be directly transferred to construction industries that are different from those where such measurements were done. Consequently, such construction industries are challenged by a lack of data on which to base their estimates which are intended for use in informing decisionmakers on the best alternatives for their circumstances. The construction industry in Uganda falls under this category of construction industries. This paper presents a study that was done to determine quantities of material and labor expected per unit for masonry and framed non-structural walls, in order to address the problem of walling systems in buildings. The study considered walling systems used within commercial, residential, and institutional buildings. Market surveys were also done to establish associated unit costs and build-ups made to determine the percentage margin differences in material and labor expended as well as overall costs between masonry and frame walling systems.

\section{Literature Review}

A wall is a component of a building that defines an area or space on a floor (Lemieux \& Totten, 2016). The most basic purpose of a wall relates to partitioning and creating a boundary for space (Lemieux \& Totten, 2016). There are other roles that walls serve in a building facility including, provision of security, shelter, soundproofing, support the roof, resistance against lateral forces (wind or earthquake), and provision of a form to the building. Walls are also used to house various types of utilities, for example, electrical wiring, plumbing, etc. Wall systems fall into two basic categories - framed walls and mass walls. Each of these categories will be discussed next.

\subsection{Framed Walls}

In framed wall systems, there are three basic components - the framing, insulation/utilities, and the finish surfaces. The supporting structure is comprised of columns or studs and other horizontal members. The finish surfaces cover up the framing elements, the insulation, and utilities within the wall, and give the wall a smooth beautiful aesthetic finish. It is the exterior part of the wall that building occupants get to experience (see, touch, and feel). This finish is usually constructed in drywall or paneling. Figure 1 shows a schematic of a framed wall with all these components.

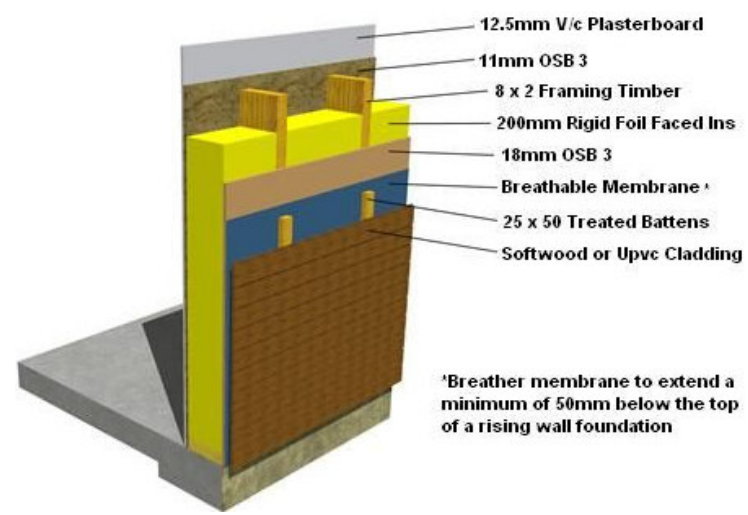

Figure 1. Anatomy of a finished framed wall

Presentations will be made on the various components of a framed wall in the following sections.

2.1.1 Framing for Framed Walls

The frame is the first component of a framed wall to be erected. This is because all the other components of the wall are mounted onto the framing. A wall frame is comprised of both vertical and horizontal elements that are assembled in such a way that it holds together and is vertically and laterally stable. The vertical members in a wall frame are referred to as studs. There are different types of studs depending on where in the frame they are located. They include wall stud, king stud, trimmer stud, etc. The horizontal members at the top and bottom of the frame are referred to as the top plate and bottom plate respectively. There are also intermediate horizontal members inserted between the top and the bottom of the frame. 


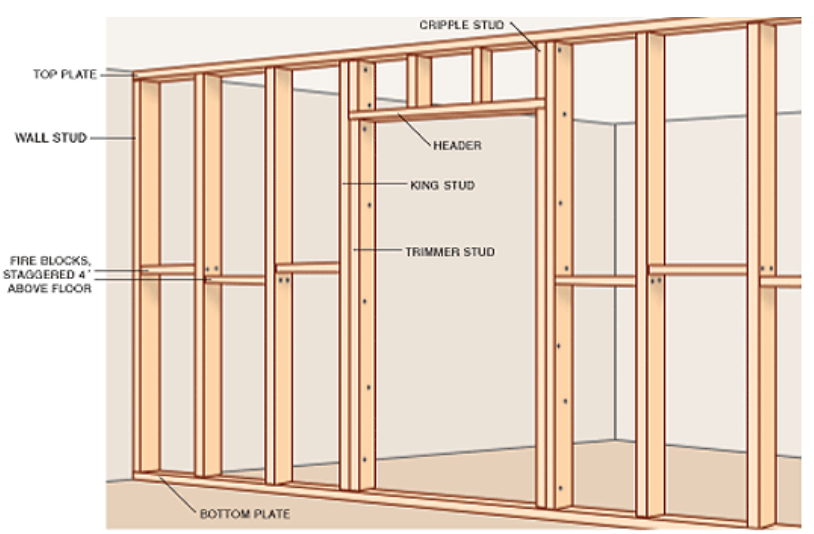

Figure 2. Different elements in the frame structure of a wall

The basic anatomy of a frame for a wall is shown in Figure 2. Different materials are used in the construction industry for the erection of wall frames. The two most commonly used are timber and metal (mainly steel and aluminum). The following sections present each of these two frame material types.

2.1.1.1 Timber Framing for Walls

Timber is a product from trees and can either be classified as hardwood or softwood (Designing Buildings, 2019). In most industries around the world, hardwood is generally more expensive than softwood. This is because softwood is obtained from trees that grow quickly and produce wood that is lighter, coarser-grained and not as strong as hardwood. Hardwood is typically used for flooring, decking, and furniture (doors, windows, and door frames) while softwood is often used for framework and cladding. The fact that softwood trees can be sustainably be grown and the softwood products are economical explains its extensive use within the building construction industry for purposes of erecting wall frames and roof trusses. A typical application of softwood in residential building projects is shown in the pictures in Figure 3.

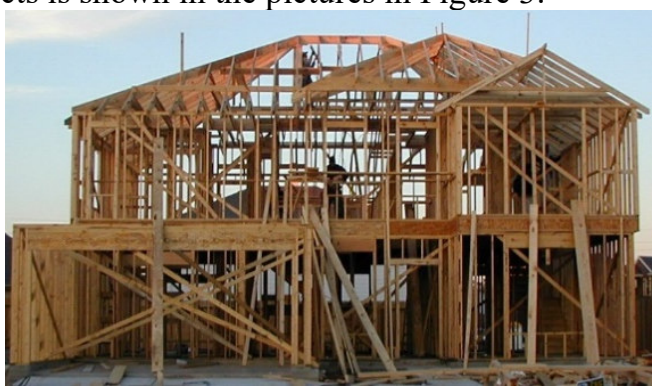

(a)

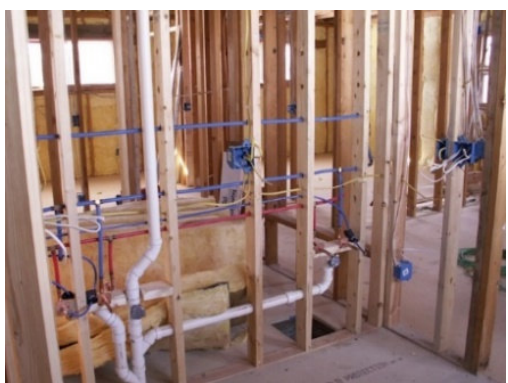

(b)

Figure 3. Pictures showing softwood being used in the construction of (a) wall and roof frame and (b) wall frame with embedded utilities for a residential house

Timber as a construction material has several pitfalls. First, timber has poor fire resistance properties. Timber starts to mold and rot when exposed to moisture and humid conditions. Timber is also susceptible to attack from insects (like ants), especially if not treated appropriately before use.

2.1.1.2 Steel Framing for Walls

Metal as a construction material has the advantage of easy assembly on site. In framed walls, the assembly is usually accomplished by joining different pieces together. Metals generally have superior strength properties to timber. They are also not attacked by insects and are therefore more durable in this aspect. Metals also have superior fire resistance properties than timber. Steel is often the metal of choice for use in framed walls. However, other metals such as aluminum are also used for the same purpose. The capital cost of metals is known to be generally higher than that for timber in most parts of the world. Steel frames are a preferred choice of material for framed walls in commercial, institutional, and high-rise residential buildings because of its good strength, durability, and fire resistance properties and the fact that these are building facilities of high importance. Figure 4 shows pictures of erected steel wall frames in a high-rise commercial building. 


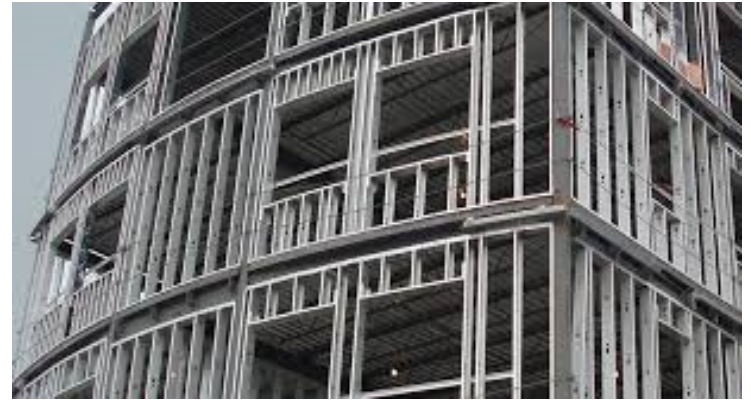

(a)

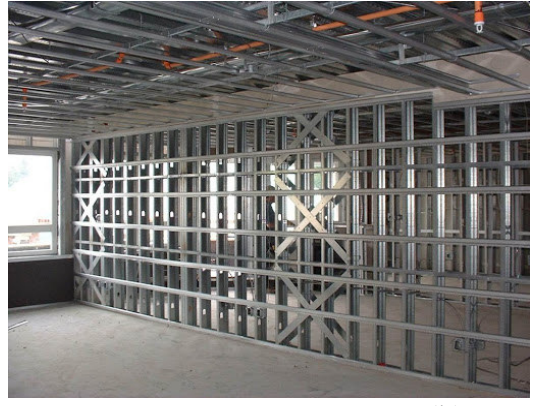

(b)

Figure 4. Photos showing steel frames erected for (a) exterior walls of building envelop, and (b) interior partition walls in a high-rise building

\subsubsection{Utilities}

There are a number of utilities that are an integral part of a building. These include electricity, water, sewerage, heating or cooling, the internet, etc. The majority of these require lines to be run to outlets. These lines are often installed within walls so that they are not left exposed for performance, safety, and aesthetic reasons. In framed walling systems, these lines are installed soon after the wall frame structure has been erected. They are mounted on to and supported by the frame. Once this is completed, insulation and other works proceed on the wall.

\subsubsection{Wall Insulation}

Frame walls would experience a lot of insulation problems if there were erected and left bare. Consequently, installation is installed into the wall core so that a more comfortable and consistent indoor climate is achieved while significantly improving your home's energy efficiency.

Various materials are utilized in the manufacture of wall frame insulation. Common ones include: fiberglass, cellulose (recycled paper fiber), rock wool, sheep's wool, latex, polyurethane, polystyrene, icynene plastic, etc. Each of these materials come in different forms and are put in place using different methods depending on the form that the insulation is in. For example, loose-fill insulation such as fiberglass or cellulose is blown or sprayed using pneumatic equipment into hard to reach areas such as attics, wall cavities, etc. Insulation rolls and batts are laid and attached to the surface to be insulated, e.g. attics, floors, walls, etc. where long runs are needed. Foam board insulation uses rigid panels of polystyrene and polyurethane that are nailed to surfaces that are being insulated. These are used in almost all parts of a building. Latex or polyurethane spray foam is used to fill small gaps and cracks.

2.1.4 Wall Panel Finish

2.1.4.1 Dry Wall

Drywall is made primarily from gypsum, a hydrated compound of calcium sulphate $\left(\mathrm{CaSO}_{4} \bullet 1 / 2 \mathrm{H}_{2} \mathrm{O}\right)$. Gypsum is mixed with paper, fiberglass, plasticizer, foaming agent, and additives that modify its performance during its service life (Manfred, 2006). The regular gypsum board does not contain additives. Binder is also added to hold ingredients together. The final product is created by sandwiching a core of the wet mixture between two sheets of heavy paper or fiberglass mats, after which it is cured till it is dry, strong, and rigid (Manfred, 2006).

Drywall is manufactured in different thicknesses and sizes. For example, the lengths of drywall panels in the US and Canada are mostly $4.9 \mathrm{~m}$, but their widths vary, with the common ones being $1.2 \mathrm{~m}, 1.4 \mathrm{~m}$, and $2.4 \mathrm{~m}$. Common panel thicknesses include $13 \mathrm{~mm}, 16 \mathrm{~mm}$. Other thicknesses that can be found and are typically used in specialized applications include $6.4 \mathrm{~mm}, 9.5 \mathrm{~mm}, 19.1 \mathrm{~mm}$, and $25.4 \mathrm{~mm}$.

There are different variants to the regular drywall that are intended to boost sound control, Water damage and mold control, fire resistance, etc. For example, type X drywall is comprised of special glass fibers are intermixed with the gypsum to reinforce the core of the panels to reduce the size of the cracks formed when the water of crystallization in gypsum is driven off during a fire, hence extending the time that gypsum boards resist fire without failure (USG, 2015). USG (2015) also states that there is another type of gypsum board that has better fire resistance properties that the type X gypsum. It is referred to as type C gypsum board. USG (2015) further states that type $\mathrm{C}$ gypsum board is similar in composition to Type X, except it comprises more glass fibers and a form of vermiculite, used to reduce shrinkage of the gypsum when the water of crystallization evaporates when exposed to high heat hence preventing the early formation of cracks that are responsible for its early collapse in fires.

There are three types of gypsum boards that have been developed specifically to provide resistance to moisture. They include greenboard, blueboard, and cementboard. In greenboard, a green-colored paper is used as a covering when making the gypsum board. This green paper contains an oil-based additive that provides moisture resistance. It is commonly used in washrooms and other areas expected to experience elevated levels of humidity (Myron, 2002). On the other hand, blueboard is comprised of blue face paper forms a strong bond with a skim coat or a built-up plaster finish providing both water and mold resistance (Manfred, 2006; Myron, 2002; Wallender, 2019). The third type of water-resisting board, the cementboard, is said to be more water-resistant than greenboard. 
It is used in showers or sauna rooms, and as a base for ceramic tile (Wallender, 2019).

Another type of special gypsum board is one that dampens sound. There are two examples under this category - soundboard and soundproof drywall. Both board types have more material packed into the gypsum to increase its density and dampening effects. Soundboard has more wood fibers added while soundproof drywall has dampening polymers mixed with the gypsum and then placed in laminates.

2.1.4.2 Dry Wall Construction

Construction of drywall begins with the cutting of the panels to the required sizes. This is usually done with a Tsquare and a cutting tool. Then, provisions for features such as outlets and light switches are cut out using a keyhole saw or a high-speed bit in a rotary tool. The prepared drywall is then fixed onto the wall framing using either nails, drywall screws together with glue. Drywall fasteners (also referred to as drywall clips or stops) are also increasingly being used for the same purpose especially at drywall corners, for providing support.

After attaching the drywall to wall studs/columns, the seams between the drywall sheets are concealed with joint tape and layers of joint compound (also referred to as mud). The joint compound is applied with a tool referred to as a taping knife or putty knife. The joint compound is also applied to any defective spots (e.g. holes) and overall screw heads. The applied joint compound is then allowed to cure before sanding is done in preparation for painting. There are times that a thin layer of finishing compound (skim coat), is applied to the entire surface to minimize the differences between the mudded areas and paper after painting. Veneer plastering is then done using a special compound that is a mixture of gypsum and lime putty. A coat or multiple coats of paint can then be applied.

\subsection{Masonry Walls}

Masonry walls are solid in nature and are either constructed as a continuum of material or from discrete units assembled together. The first type is mostly constructed in plain or reinforced concrete material. In this study, the focus is on masonry walls constructed using discrete units. The discrete units used in the erection of solid walls are either made from light concrete, clay, or mud/lateritic soils. These units are produced in various shapes, sizes, textures, and colors (Hatzinikolas \& Korany, 2005). There are two broad categories of masonry walling units based on the criteria for form - solid units and hollow units. According to Hatzinikolas \& Korany (2005), the percentage of void in the bearing plate of the walling relative to this plate's gross cross-section area is the criteria used for qualifying a wall units as either solid or hollow. A hollow wall unit will have its void ratio exceeding $25 \%$ (Hatzinikolas \& Korany, 2005). Hollow wall units are mainly used in the construction of structural masonry walls and require significantly more time and effort to construct. This study is not covering this type of walling units as these are reserved for specialized applications. Solid wall units covered in this study can be sub-categorized based on size criteria hence: blocks and bricks. Blocks are mostly made from light concrete and have a much higher capital cost than bricks (at least 10 times higher). Blocks are larger than bricks in size and are often a nominal size of 40mm long, 200mm wide, and 200mm higher (Bailey, 2017). According to Bailey (2017), the width of a block can be reduced in steps of $50 \mathrm{~mm}$ until a minimum of $100 \mathrm{~mm}$. Bricks are made in a smaller size with most being about 230mm long, 110mm wide, and 76mm high (Bailey, 2017).

2.2.1 Production of Blocks and Bricks

Blocks and bricks are produced so that they achieve certain construction and functional requirements. Several requirements need to be fulfilled when erecting walls from discrete units so that they perform well. First, the vertical joints need not be continuous, then the horizontal joints need to be parallel and perfectly horizontal. Last, the wall needs to be perfectly plumb. These joints can be in two types depending on the form of the building wall units. The first type is referred to as dry joints. This type is used when the wall units are produced with interlocking grooves. The interlocking features eliminate the need for the bonding material. The second type of joint is referred to as mortar joints. Mortar joints are used when wall units are plain and have no interlocking features. The interlock between the wall units is provided by the mortar joints.

Blocks and bricks are made using different materials for example light concrete, clay, laterite, etc. When light concrete is the choice of material, the light concrete mix is produced either by hand or machine from fine aggregate, cement, and water as basic ingredients. Light concrete mixture is loaded into a mould, compacted, and then released from the mould. These are then transported to a curing area where the curing process takes place.

Blocks or bricks made from clay or laterite first have the clay or laterite mixed in water to make a stiff mixture. Once this mixture has been prepared, it is loaded into a mould and compacted. Thereafter, it is removed from the mould and laid down on the ground to cure. After curing, the blocks or bricks are arranged in a stack or feed into a kiln ready to be fired up. Once ready, the firing is commenced and blocks/bricks baked at temperatures in the range $900^{\circ} \mathrm{C}-1300^{\circ} \mathrm{C}$. In the clay material, a ceramic fusion process called vitrification takes place at that temperature (Hatzinikolas \& Korany, 2005). This firing increases strength and controls the color of brick or block. The blocks/bricks are then left to cool off before they are deemed ready for use on construction sites.

2.2.2 Construction Styles for Blocks and Bricks

Walls are erected in different styles using discrete walling units. These styles are differentiated by the fashion in why the walling units are stacked over one another, i.e. the orientation of the wall units. The first style used in the 
construction of masonry walls is referred to as a stretcher bond. In the stretcher bond, the walling units are placed with their length parallel to the length of the wall. The second wall style used in the erection of a wall is referred to as a header bond. In this header bond, the walling units are oriented in such a way that the length of the walling units is perpendicular to the longer side (or length) of the wall. The third type of bonding style is referred to as the English bond. In the English bond, the two successive courses of blockwork are erected in different bonding styles with one being in the header bond and the subsequent one being in a stretcher bond. The last bonding style used in wall erection is the Flemish bond. In the Flemish bond, the orientation of wall units is changed within each course. Two wall units are placed in the stretcher bond then followed by one wall unit in the header bond and then this sequence is repeated throughout the course. Figure 5 shows the different bonding styles discussed.

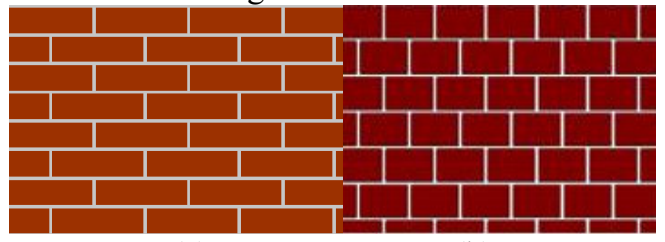

(a)

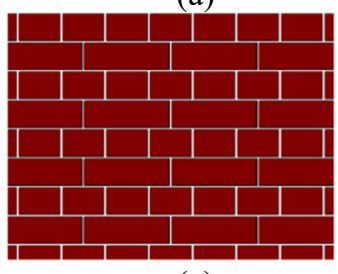

(c) (b)

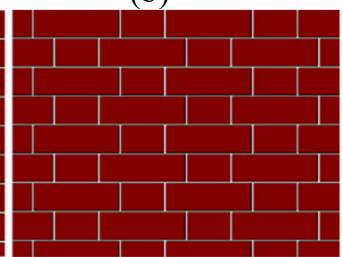

(d)

Figure 5. Wall bonding styles used in construction - (a) stretcher, (b) header, (c) English, and (d) Flemish

\subsection{Time and Motion Studies}

Time and motion studies are often mistaken to be the same thing yet, in fact, they are different in the way that they are implemented and in the use of their results. Time study methods were pioneered by Frederick Winslow Taylor (Krenn, 2011) while motion studies were pioneered by Frank and Lillian Gilbreth (Baumgart \& Neuhauser, 2009). Today, both methods are said to belong to an integrated work systems approach known as methods engineering.

Payne, Youngcourt \& Watrous (2006) state that at the most basic level, time study methods involve breaking down a job into parts, timing each part, and if necessary rearranging the parts into the most efficient method of working. In time studies, there is a direct and continuous observation of a task and measurement using stopwatches or videotape cameras to track the amount of time needed to complete the task. The technique allows for adjustments in the measured time which account for breaks, delays, fatigue-induced rest periods, personal needs, etc. (Payne et al, 2006). Time studies are mainly used to generate time-based benchmarks related to the performance of tasks. The technique can also be used to re-sequence activities to minimize the overall completion time.

Motion studies are said to have been motivated by Taylor's time studies (Baumgart \& Neuhauser, 2009). Motion studies involve observing and analyzing the body posture of workers while carrying out their tasks, i.e. work motion. The observation piece is often done by filming/videotaping the workers as they carry out their activities. This creates a visual record of how work is performed which can serve as a basis for two things. First, the visual recordings can serve as a basis for any diagnostic work that may be needed in the identification of areas of work performance that could require improvement. Second, the visual record obtained can be used for purposes of training workers on the best way to perform their work, i.e. healthy, safely, and in a timely fashion. Ergonomic aspects deciphered from video footage postures are mainly used to foster the health and welfare of individual workers while they engage in work tasks. Postures and maneuvers performed during work execution can be to understand safety issues related to an individual, crews, and an entire work environment.

From the discussion presented, it can be noted that results from time studies can mainly be applied towards production rate and productivity monitoring and improvements. Motion studies, on the other hand, can feed into numerous aspects such as production rate, productivity, quality, health, and safety, etc. Strictly speaking, it can be said that motion studies seem to have broader applications than time studies. However, both have their place in management science hence cannot do away with either.

\section{Methodology}

Surveys were conducted to establish the different types of materials that are used in the erection of framed walls and masonry walls. Interviews were conducted with different construction industry practitioners such as those working in consultancy firms (i.e. civil engineers, architects, quantity surveyors) and those engaged in the actual building onsite as either main contractors or sub-contractors. Individuals interviewed on the contractors and subcontractors' side included project managers, site engineers, and their assistants, clerks of works, foremen, 
experienced tradesmen, etc. Interviews were performed on-site and off-site (mainly at head offices). Interview schedules were prepared and utilized to guide this process. A mixed approach was used which involved a blend of both structured, semi-structured, and unstructured interviews. This was customized to suit the interviewee's education level, experience, and the amount of time they were willing to put aside to be interviewed.

First, a list of material items used in the construction of walls was generated for each wall type. Next, the quantities of each material item that is required to erect a unit of the wall for each wall type were also determined. To ensure consistency and simplicity, the unit of work that was considered was $1 \mathrm{~m}^{2}$ of the finished wall. After, quantities for different items required to construct a unit of wall type had been established, work on finding prices commenced. Quick takeoff calculations were done by the researchers for sample standard designs as part of the verification and validation of the data that was collected from practitioners.

Unit prices of materials and material quantities are the fundamental building blocks for pricing or costing work. In order to achieve the objective of this study which involved seeking price margin differences for the different types of walls used in building construction, particularly framed walls and non-structural masonry walls, there was a need to undertake a price buildup. The price referred to here is a bare price, i.e. excluding markup for profit, overheads, contingencies, etc. This was to ensure that price comparisons for the different wall types were being made authentically without introducing other components that would cause variations that are independent of the material requirements for wall erection. Market surveys for material prices were carried out which targeted and included specialty and general-purpose vendors that deal in each material of interest. As expected, there were variations in the quotations that were provided by the vendors that were surveyed. Each of their values was recoded into a Ms. Excel file so that subsequent use in the analysis would be easy. It should be noted that unlike with material quotation data obtained, there were minimal variations that data obtained on quantities of each material item required to erect a unit of each wall type.

Once the data collection phase was completed, the data was organized and cleaned up of any errors or inconsistencies. The data on material quantity requirements was assumed to be deterministic because of their minimal variations and hence summarized in structured tables so they could easily be utilized in the price buildup analytics. On the other hand, data on unit prices were taken to be stochastic in nature because of the significance in the difference in values obtained from vendors for the same items. In order to represent this array of unit price values obtained for each item in a concise way that can be utilized in price build-up computations, probability distributions were fitted to each unique dataset using the EasyFit software. EasyFit is developed and maintained by a tech company known as MathWave. EasyFit has several goodness of fit tests that it supports such as the Kolmogorov-Smirnov, Anderson-Darling, Chi-Square, etc. All of the rankings were utilized when selecting the best distribution that fitted the data. Each ranking criterion was weighted equally and a weighted average rank score for the probability distributions was used to pick the best fit. The distribution name and their parameters were summarized in a tabular form. This marked the end of the input modeling process.

The cost/price buildup process involved performing Monte-Carlo simulation analytics given that it required arithmetic operations to be done on deterministic (i.e. the material requirement to erect a unit of wall) and stochastic state variables (i.e. the material unit cost). Simulations were implemented by writing code snippets within the Mathematica environment. Mathematica is a robust math-based scripting environment which has extensive inbuilt libraries and functions. Mathematics is developed and maintained by a tech company called Wolfram. Separate code snippets were written to perform a cost buildup for each wall type. These code snippets sampled a random deviate for the unit cost for a given item, multiplied that with the quantity of that item required to build a unit wall to obtain the cost of that item. This is done for each item for that wall type and the sum of costs for all items for that wall type found to obtain the total material costs to erect one unit of that wall type. This is computation is done in one iteration. However, in the Monte-Carlo simulation, several iterations are done with each iteration generating a cost such that at the end of the simulation, there are several costs obtained for the material required to erect a unit of that wall type. These cost results from the simulation generate a probability distribution which is typically normal with a certain mean and standard deviation. Consequently, each wall type had a normal distribution representing the cost for material to erect one unit of wall.

In order to obtain margins of difference between wall type costs, first, a control wall type was selected. The masonry wall built from earth brick was chosen for this purpose because of its extensive use with the construction industry in Uganda. Another Monte-Carlo simulation experiment was run for this purpose by writing a code snippet within the Mathematica environment. In this experiment, random deviates were sampled from each of the cost distributions for the wall types being compared and a ratio obtained between these deviates for each iteration. This was repeated for each of the several iterations within the simulation to generate a set of different ratios that follow a particular probability distribution. This distribution represented the margin difference in cost between the control wall type and the wall type being analyzed. 


\section{Input Material Quantities and Cost Data}

\subsection{Material Quantities}

Quantities for materials utilized in any construction process are one of the important parameters considered in any cost build-up effort. It is important to note that there is often a difference in the form that materials are supplied by vendors or from manufacturers and the form in which they are utilized to produce a building component. The data reported provides some details on the form in which materials are dispatched by vendors/manufacturers but also provide quantities required to produce one unit of building component, in this case, $1 \mathrm{~m}^{2}$ of wall.

4.1.1 Framed wall material quantities

The quantities of timber studs and noggins (horizontal members fixed between studs to give lateral bracing) are a function of the spacing of the timber studs. There is also a head plate, and a floor or soleplate in the assembly of the wall frame. The spacing of studs is in turn dependent on the load that the wall is carrying but typically ranges between $400 \mathrm{~mm}-600 \mathrm{~mm}$.

In timber-framed walls, there are different sizes of member pieces that can be used, i.e. 3"x2", 4"x2", 6"x2", 8 "x2", and 10"x2". Standard spacing of 500mm was assumed for the non-structural walls in this study. Besides the spacing, the material quantity also depends on the height of the framed wall. Another simplifying assumption was made in the study, i.e. that all framed walls are $2.7 \mathrm{~m}$ tall. It is also assumed that the 4"x2" timber studs are oriented in such a way that the 2 " side faces outside and is the surface onto which the gypsum board is finally attached.

Steel metal is another wall framing material that is used in construction, besides timber. It was revealed that steel framing material has some advantages over timber and they include the fact that it is lighter and does not warp. Steel frame members are connected by screws that are drilled into the material.

Specifications of gypsum board that were found to be prevalent on the market within Kampala city in Uganda were as follows. The boards were found to have a surface area that is 8 ' $x 4$ '. These boards were found to be in two gauges (thicknesses), i.e., $9.5 \mathrm{~mm}$ and $12.5 \mathrm{~mm}$. It was revealed that these boards are cut to desired sizes on site during the wall erection process. Boards are attached to timber frames by the use of nails and screws in the case of the galvanized iron metallic frames. Table 1 summarizes the quantity of material utilized to construct $1 \mathrm{~m}^{2}$ of a framed wall.

Table 1. Quantity of materials used to construct $1 \mathrm{~m}^{2}$ of framed wall

\begin{tabular}{|c|l|c|c|}
\hline$\#$ & \multicolumn{1}{|c|}{ Material } & Unit of Measure & Quantity \\
\hline 1 & Gypsum board (8'x4'-9.5mm thick) & $\mathrm{m}^{2}$ & 2.00 \\
\hline 2 & Gypsum board (8'x4'-12mm thick) & $\mathrm{m}^{2}$ & 2.00 \\
\hline 3 & Timber pieces (3'x2') & $\mathrm{m}$ & 11.95 \\
\hline 4 & Timber pieces (4'x2') & $\mathrm{m}$ & 11.95 \\
\hline 5 & Steel metal pieces (20mm Channel) & $\mathrm{m}$ & 11.95 \\
\hline 6 & Steel metal pieces (25mm Channel) & $\mathrm{m}$ & 11.95 \\
\hline 7 & Connectors (e.g. nails) & Pcs & 60 \\
\hline 8 & Connectors (e.g. screws) & Pcs & 30 \\
\hline
\end{tabular}

4.1.2 Masonry walls material quantities

The core for masonry walls is erected using discrete wall units, i.e. bricks or blocks. These discrete units are "glued" together using mortar - a paste made using a cement binder, fine aggregate (sand) and water. Once this has been erected, a plaster finish is applied using mortar.

On average, the bricks used in Uganda have dimensions that are consistent with stipulated British standards, i.e., $215 \mathrm{~mm} X 102.5 \mathrm{~mm} X 65 \mathrm{~mm}$. This was a size assumed in this study. It was also assumed that $25 \mathrm{~mm}$ mortar joints were used to bond the bricks. A mortar mix specification of 1:3 (cement: sand) by volume was also assumed for preparing the mortar used in bonding bricks and plastering the erected wall on both sides. A plaster thickness of $37.5 \mathrm{~mm}$ was assumed for the brick wall option. Quantities of materials obtained for the plastered brick wall based on these assumed specifications are summarized in Table 2. These are material quantities required to construct $1 \mathrm{~m}^{2}$ of a plastered brick wall.

Table 2. Quantity of material required to build $1 \mathrm{~m}^{2}$ of masonry brick wall

\begin{tabular}{|c|l|c|c|}
\hline$\#$ & \multicolumn{1}{|c|}{ Material } & Unit of Measure & Quantity \\
\hline 1 & Cement (Binder) & $\mathrm{Kg}$ & 52.66 \\
\hline 2 & Sand (Fine aggregate) & $\mathrm{m}^{3}$ & 0.105 \\
\hline 3 & Bricks (215mmX102.5mmX65mm) & $\mathrm{Pcs}$ & 34 \\
\hline
\end{tabular}

Quantities of cement and sand presented in the Table above are totals required to prepare mortar used in both the bonding and plastering. It is worth noting that of this, $45.47 \%$ was utilized in bonding the bricks together while $54.53 \%$ was used in plastering the erected brick wall.

Walls erected using blocks made use of these walling units that are an average size of $400 \mathrm{~mm} X 200 \mathrm{~mm} \times 200 \mathrm{~mm}$. It was assumed that in practice, blocks are assembled with mortar joints that are $25 \mathrm{~mm}$ thick. It is also assumed that the thickness of the mortar plaster used to finish the wall is $25 \mathrm{~mm}$. A $1: 3$ (cement: 
sand) mortar mix specification was also assumed for preparing mortar used in joints and plaster finish. Quantities of materials required to erect $1 \mathrm{~m}^{2}$ of finished block wall in the assumed specifications are summarized in Table 3 .

Table 3. Quantity of material required to build $1 \mathrm{~m}^{2}$ of masonry block wall

\begin{tabular}{|c|l|c|c|}
\hline$\#$ & \multicolumn{1}{|c|}{ Material } & Unit of Measure & Quantity \\
\hline 1 & Cement (Binder) & $\mathrm{Kg}$ & 32.57 \\
\hline 2 & Sand (Fine aggregate) & $\mathrm{m}^{3}$ & 0.065 \\
\hline 3 & Blocks (400mmX200mmX200mm) & $\mathrm{Pcs}$ & 11 \\
\hline
\end{tabular}

It was revealed that of this total quantity of cement binder and sand reported in the Table above, $42.20 \%$ of it was utilized within the joints while $57.80 \%$ was utilized in the mortar used for plastering.

It is worth noting that cement which is used as a binder is sold in $50 \mathrm{Kg}$ bags with each bag having an estimated volume of $0.0332 \mathrm{~m}^{3}$. The density of the cement is approximately $1506 \mathrm{Kg} \mathrm{m}^{-3}$. The quantities obtained are based on these attributes of the cement binder.

\subsection{Material Unit Prices}

The unit prices for the materials were based on those obtained from the venders in Kampala, Uganda in 2019. The currency used was the Uganda Shilling (UGX). At that time, the exchange rate quoted by the Uganda central bank (Bank of Uganda) was approximately $1 \mathrm{USD}=3,700 \mathrm{UGX}$. This information is provided for the benefit of readers that may want to apply research findings in this paper in their practice especially in industries outside Uganda. Such efforts may also require to factor in inflation rates using 2019 as the base year.

4.2.1 Framed Wall Material Unit Prices

The costs for different material options that are commonly used in the erection of framed walls are presented. Those used in timber frames are put together with those used in metal frames. The costs of timber studs varied depending on the vendor that provided the quote and the type of timber that was quoted for, i.e. pine or eucalyptus. The costs for the different gauges of gypsum board are also represented. Values for the raw data collected are not presented in the table as that would be meaningless. Rather statistics for this data were computed and summarized in Table 4.

Table 4. Statistics on the cost of different materials used in frame wall construction

\begin{tabular}{|c|c|c|c|c|}
\hline Statistic (UGX) & Timber & Metal & $\begin{array}{c}\text { Gypsum board } \\
(9.5 \mathrm{~mm})\end{array}$ & $\begin{array}{c}\text { Gypsum board } \\
(12.5 \mathrm{~mm})\end{array}$ \\
\hline Minimum & 11800.00 & 16600.00 & 40700.00 & 50800.00 \\
\hline Maximum & 13300.00 & 18900.00 & 44300.00 & 54700.00 \\
\hline Mean & 12386.82 & 17987.90 & 42203.90 & 52542.30 \\
\hline Standard deviation & 442.50 & 631.61 & 1002.79 & 832.32 \\
\hline First quartile $\left(\mathrm{Q}_{1}\right)$ & 12091.96 & 17711.30 & 41510.10 & 51850.10 \\
\hline Median $\left(\mathrm{Q}_{2}\right)$ & 12360.01 & 18104.10 & 42124.90 & 52660.50 \\
\hline Third quartile $\left(\mathrm{Q}_{3}\right)$ & 12627.52 & 18382.70 & 42873.10 & 53126.30 \\
\hline
\end{tabular}

Also, data models that can be directly input into simulation experiments were used to represent the values in the raw cost datasets. These data models were comprised of probability distributions which were fitted in an input modeling process using a software known as EasyFit. Best fitting probability distributions for the cost of each material are summarized in Table 5.

Table 5. Probability distributions for unit costs for materials used to erect framed walls

\begin{tabular}{|l|c|c|}
\hline \multicolumn{1}{|c|}{ Frame wall construction material } & $\begin{array}{l}\text { Unit of } \\
\text { measure }\end{array}$ & Probability distribution for unit cost (UGX) \\
\hline $\begin{array}{l}\text { Timber, rectangular section (4'x2"-12' } \\
\text { length) }\end{array}$ & Pc & JohnsonSB(0.48278,0.88711,2023.6,11591) \\
\hline $\begin{array}{l}\text { Steel, C-section (4'x4"-16' length, 3mm } \\
\text { gauge) }\end{array}$ & Pc & Weibull(32.1,18248.0) \\
\hline Gypsum board (8'x4'-9.5mm thick) & Pc & Log-Logistic(70.73,42122.0) \\
\hline Gypsum board (8'x4'-12.5mm thick) & Pc & Gumbel $(648.96,52917.0)$ \\
\hline
\end{tabular}

The graphical results for the probability distributions which were fitted to the framed wall material price data were summarized in the Figure 6. 

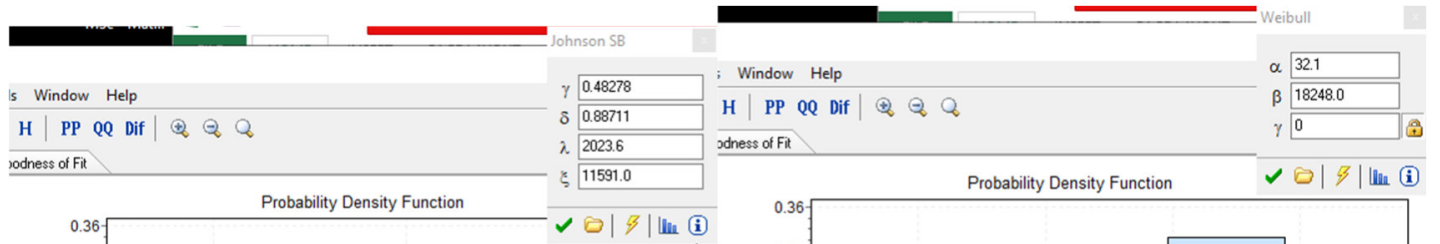

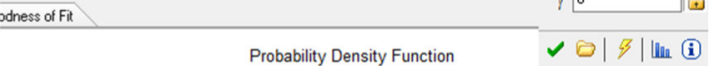
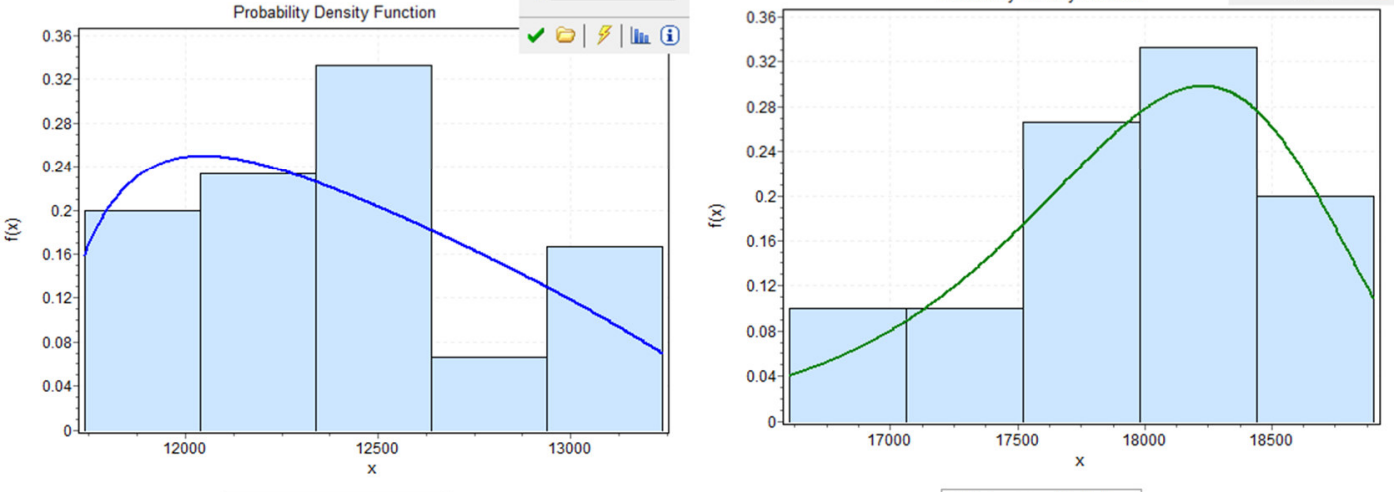

CHistogram — Johnson SB

(a)

(b)
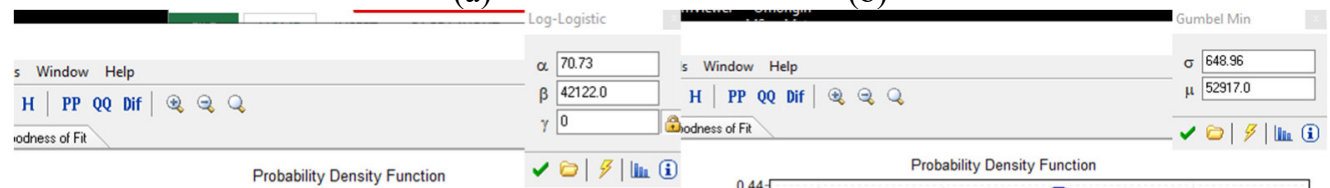

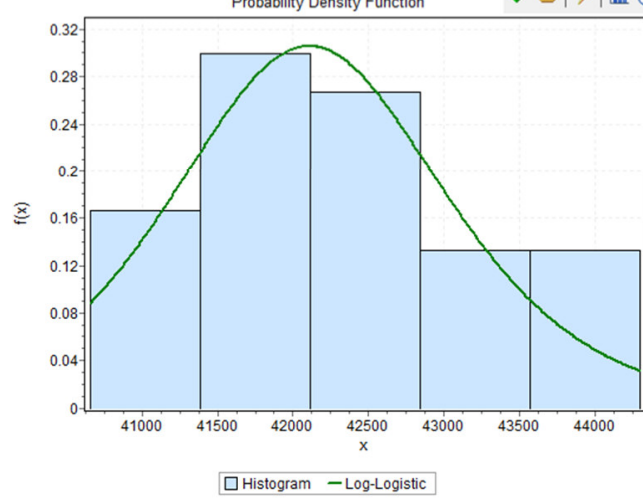

(c)

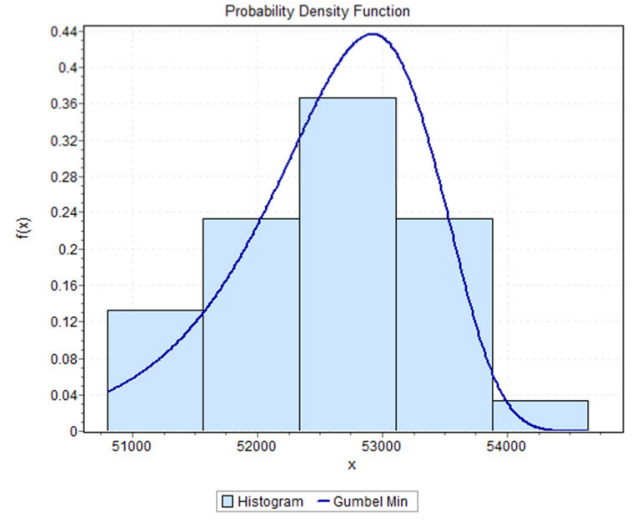

(d)

Figure 6. Fitted probability distributions for unit costs of (a) timber, (b) metal, (c) $9.5 \mathrm{~mm}$ gypsum board and (d) $12.5 \mathrm{~mm}$ gypsum board

Connectors are a set of accessories that are used to create an assembly for the wall framing. These connectors vary depending on the type of material used for the framing members. Nails are the preferred option when the framing members are made out of timber. Screws are used as connectors when steel is used as the framing material. Market surveys indicate that screws cost significantly more than nails. Details are summarized in the following table. Although vendors usually trade connectors by weight, transformations were made to align units of measure used to quote quantities in unit rate data to units of measure used to quote the material quantities used to erect a $1 \mathrm{~m}^{2}$ of wall type. Interviewed revealed that mainly 4" nails and 4" screws are utilized in timber and steel wall frame construction. Data for these other screw and nail sizes have been provided for the readers' information.

Table 6. Prices for different connectors used in the erection of framed walls

\begin{tabular}{|c|l|c|c|c|c|}
\hline$\#$ & Material & Unit of Measure & Pcs in a Kg & Unit Price (UGX/Kg) & Unit Price (UGX/Pc) \\
\hline 1 & 2"Nails & $\mathrm{Kg}$ & 100 & 6,500 & 65.00 \\
\hline 2 & 3"Nails & $\mathrm{Kg}$ & 70 & 6,000 & 85.71 \\
\hline 3 & 4"Nails & $\mathrm{Kg}$ & 50 & 5,500 & 110 \\
\hline 4 & 2" Screws & $\mathrm{Kg}$ & 110 & 77,000 & 700 \\
\hline 5 & 3" Screws & $\mathrm{Kg}$ & 80 & 48,000 & 600 \\
\hline 6 & 4" Screws & $\mathrm{Kg}$ & 60 & 30,000 & 500 \\
\hline
\end{tabular}

4.2.2 Masonry Wall Material Unit Prices

Materials used in the erection of a masonry wall core include mortar and bricks or blocks. The cost of water used in preparing the mortar is ignored in this analysis. Costs collected from different vendors for each of these items were obtained. Statistics for these cost values obtained were summarized in the following table. 
Table 7. Statistics on the unit prices of materials used in the construction of masonry walls

\begin{tabular}{|c|c|c|c|c|}
\hline Statistic $(U G X)$ & Cement & Sand & Brick & Block \\
\hline Minimum & 27400.00 & 22400.00 & 300.00 & 3300.00 \\
\hline Maximum & 32100.00 & 30750.00 & 350.00 & 3500.00 \\
\hline Mean & 30283.70 & 25607.50 & 322.54 & 3392.83 \\
\hline Standard deviation & 1282.84 & 2328.91 & 7.63 & 41.03 \\
\hline First quartile $\left(\mathrm{Q}_{1}\right)$ & 29718.60 & 23906.20 & 316.34 & 3366.87 \\
\hline Median $\left(\mathrm{Q}_{2}\right)$ & 30511.70 & 25240.80 & 322.66 & 3389.99 \\
\hline Third quartile $\left(\mathrm{Q}_{3}\right)$ & 31341.70 & 27129.80 & 328.36 & 3421.06 \\
\hline
\end{tabular}

Besides the statistics that were computed for the data, probability distributions were fitted to the data on material unit prices using the EasyFit software. The probability distributions that showed the best fit were summarized in Table 8 and Figure 7.

Table 8. Probability distributions for unit costs for materials used to erect masonry walls

\begin{tabular}{|c|c|c|}
\hline Masonry wall construction material & Unit of measure & Probability distribution for unit cost (UGX) \\
\hline Cement $(50 \mathrm{Kg})$ & $\mathrm{Kg}$ & JohnsonSB(-0.8504,0.7936,5939.7,26156.0) \\
\hline Sand & $\mathrm{m}^{3}$ & Weibull(1.3946,3659.2,22252) \\
\hline Brick & $\mathrm{Pc}$ & Uniform $(309.32,335.76)$ \\
\hline Block & $\mathrm{Pc}$ & JohnsonSB $(0.27422,2.2264,383.94,3212.1)$ \\
\hline
\end{tabular}

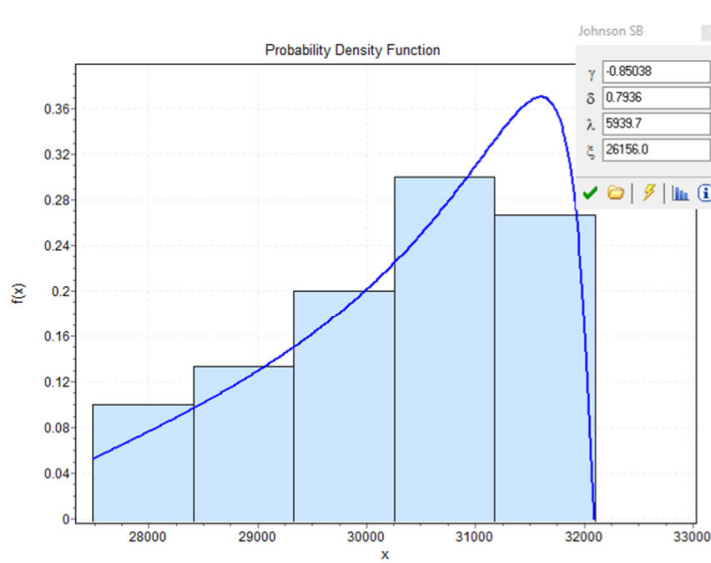

(a)

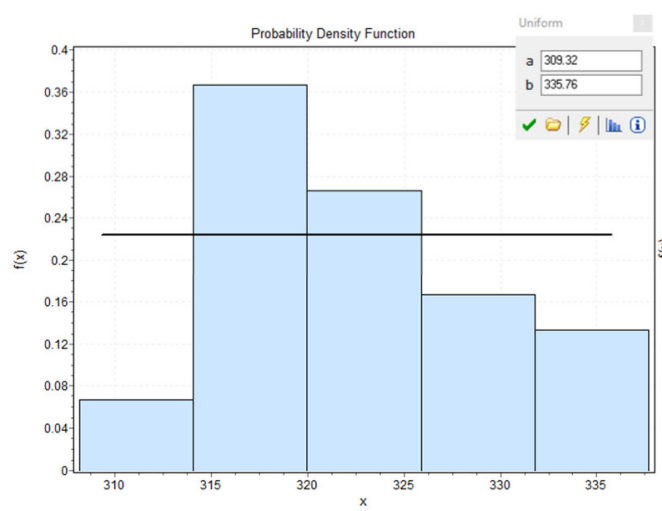

(c)

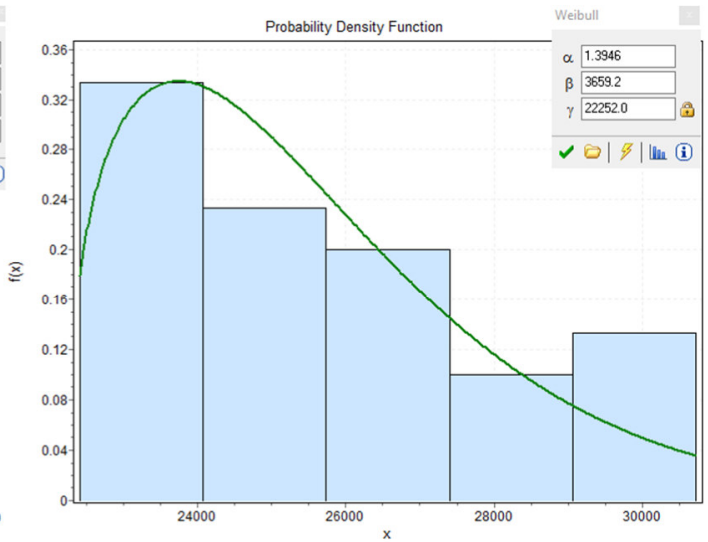

(b)

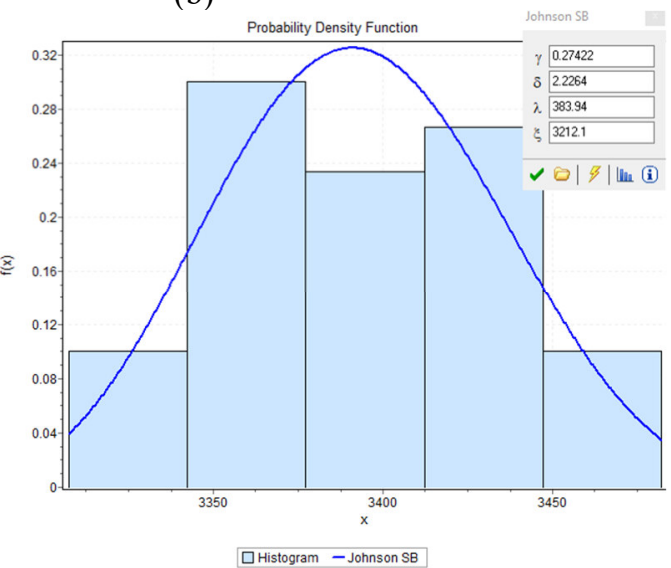

(d)

Figure 7. Fitted probability distributions for unit costs of (a) cement, (b) sand, (c) bricks, and (d) blocks

\section{Unit Wall Cost Build-up}

In order to determine the relative margin of difference in material costs between the different wall types, it was necessary to have the material costs to erect $1 \mathrm{~m}^{2}$ of that wall type. This was done using the data collected on the quantities of each material item required to build $1 \mathrm{~m}^{2}$ of a given wall type and the unit cost of each of these cost items. Values for each of these have been reported in the previous section for each wall type - framed and masonry wall (at a high-level). At a lower level, framed walls were sub-divided into several types, i.e. timber-framed finished in $9.5 \mathrm{~mm}$ gypsum board, timber-framed finished in $12.5 \mathrm{~mm}$ gypsum board, metal-framed finished in 
$9.5 \mathrm{~mm}$ gypsum board, and metal-framed finished in $12.5 \mathrm{~mm}$ gypsum board. Sub-divisions for masonry wall included brick wall and block wall.

Given that the material item quantities were deterministic in nature while the unit prices for these material items were stochastic in nature, Monte-Carlo simulation experiments were set up for each wall type to build-up the material cost required to construct $1 \mathrm{~m}^{2}$ of that type of wall. Code snippets were written and executed within the Mathematica environment for this purpose. Each of these simulations was seeded and 1,000 iterations performed within each experiment. The details of the code written in Mathematica for one masonry wall type and one framed wall type are presented next. The first code is for a timber-framed wall finished with a $9.5 \mathrm{~mm}$ gypsum board. The code presented after this one is for a masonry brick wall.

(*Cost build-up: Masonry brick Wall*)

Clear [Cost50kgscement, Cost1m3sand, Cost1brick, Cementquantity, Sandquantity, Brickquantity,

Brickwallunitcost, Totaliterations] ;

SeedRandom [1 234 567]

Totaliterations $=1000$;

Cementquantity $=52.60$

Sandquantity $=0.105$;

Brickquantity $=34$;

Brickwallunitcost $=\{\}$;

For [

$i=1$,

is Totaliterations,

i++,

(*The cost of 50 Kgs of cement $*)$

Cost50kgscement $=$ RandomVariate $[$ JohnsonDistribution $[" \mathrm{SB} ",-0.8504,0.7936,5939.7,26156.0]]$;

( $*$ The cost of $1 \mathrm{~m} 3$ of sand*)

Cost1m3sand = RandomVariate [WeibullDistribution $[1.3946,3659.2,22$ 252] ] ;

(*Cost for each single brick*)

Cost1brick $=$ RandomVariate [UniformDistribution $[\{309.32,335.76\}]]$;

Clear [Totalcost]

Totalcost $=($ Cementquantity $*$ Cost50kgscement $/ 50)+($ Sandquantity $*$ Cost1m3sand $)+($ Brickquantity * Cost1brick $)$;

Brickwallunitcost $=$ AppendTo [Brickwallunitcost, Totalcost $]$

] ;

The code in Mathematica was executed and results obtained. Statistics of the results were computed for the unit costs for materials used to erect the different types of walls. The results were obtained from simulation experiments that hypothetically modeling the construction of 1,000 walls of each type and tracked material costs. The statistics in UGX $/ \mathrm{m}^{2}$ are summarized in Table 9.

Table 9. Statistics of material costs expended to erect $1 \mathrm{~m}^{2}$ of various types of walls

\begin{tabular}{|l|c|c|c|c|c|c|}
\hline \multicolumn{1}{|c|}{ Statistics } & $\begin{array}{c}\text { Masonry - } \\
\text { Brick }\end{array}$ & $\begin{array}{c}\text { Masonry } \\
\text { Block }\end{array}$ & $\begin{array}{c}\text { Timber } \\
\text { Framed \& } \\
9.5 \mathrm{~mm} \\
\text { Gypsum }\end{array}$ & $\begin{array}{c}\text { Timber } \\
\text { Framed \& } \\
12.5 \mathrm{~mm} \\
\text { Gypsum }\end{array}$ & $\begin{array}{c}\text { Metal } \\
\text { Framed \& } \\
9.5 \mathrm{~mm} \\
\text { Gypsum }\end{array}$ & $\begin{array}{c}\text { Metal Framed } \\
\text { 12.5mm } \\
\text { Gypsum }\end{array}$ \\
\hline Minimum & 21994.3 & 19275.6 & 40494.7 & 48190.8 & 77019.6 & 84290.7 \\
\hline Maximum & 48080.9 & 52346.5 & 77955.3 & 85313.3 & 93023.4 & 97800.2 \\
\hline Mean & 39150.3 & 38137.7 & 56102.1 & 63118.2 & 87211 & 94231.8 \\
\hline Standard Deviation & 6061.44 & 5488.75 & 8460.96 & 8390.45 & 1905.02 & 1910.65 \\
\hline First Quartile (Q1) & 35053.1 & 34551.6 & 49103.9 & 56331.3 & 86253.5 & 93349.1 \\
\hline Median (Q2) & 40596.3 & 38435.7 & 55172.8 & 62001.6 & 87466.9 & 94590.3 \\
\hline $\begin{array}{l}\text { Third Quartile } \\
\text { (Q3) }\end{array}$ & 44230.3 & 41966.7 & 61695.2 & 68649.8 & 88521.3 & 95545.1 \\
\hline
\end{tabular}

The random values obtained for the cost per $\mathrm{m}^{2}$ of a wall from the simulations were also subjected to probability distribution fitting analytics. The EasyFit software was used for this purpose and the best fitting distributions for each wall type selected. These are summarized in Figure 8. 


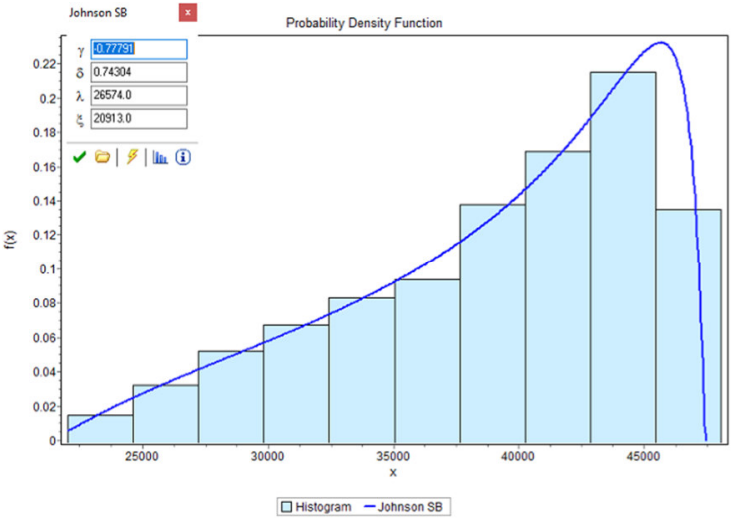

(a)

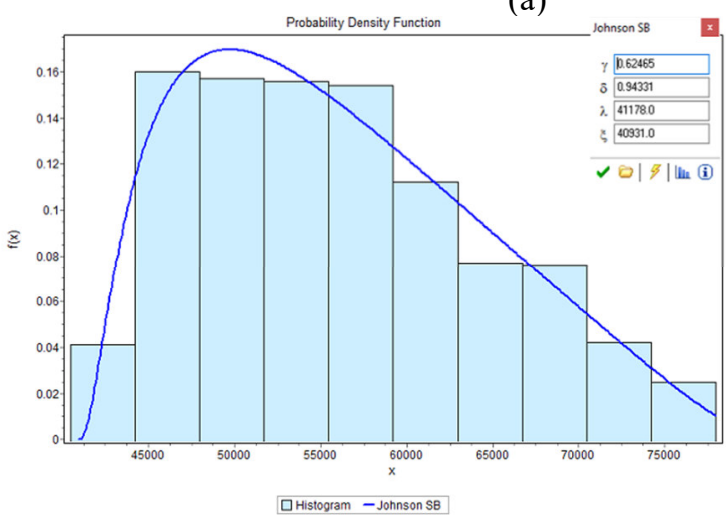

(c)

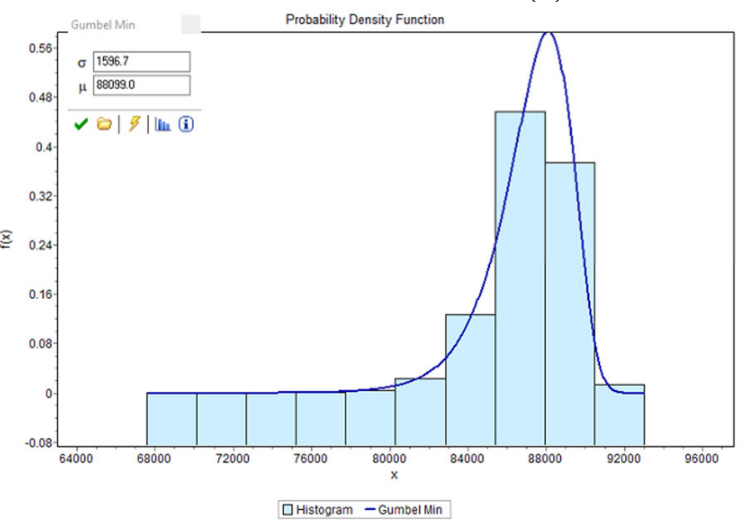

(e)

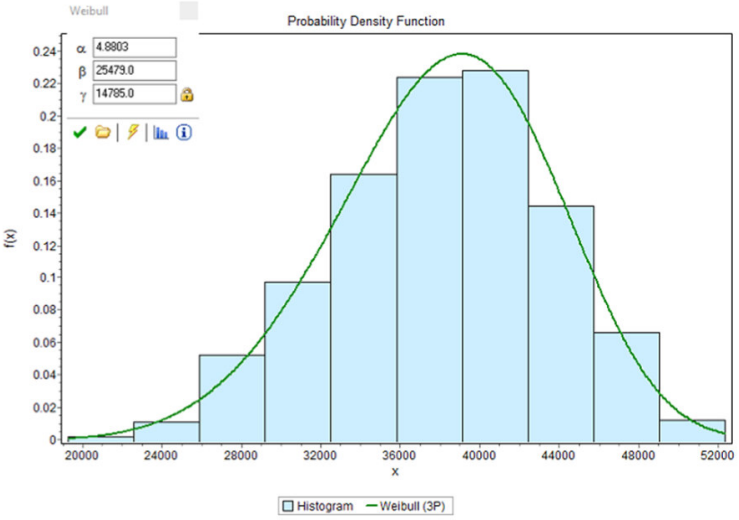

(b)

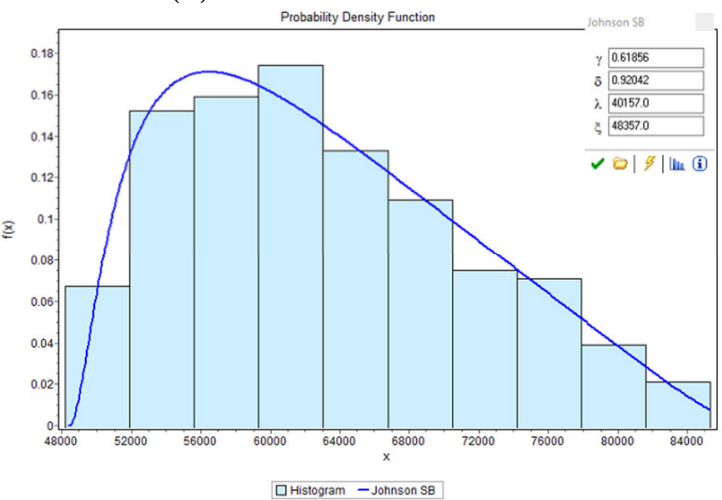

(d)

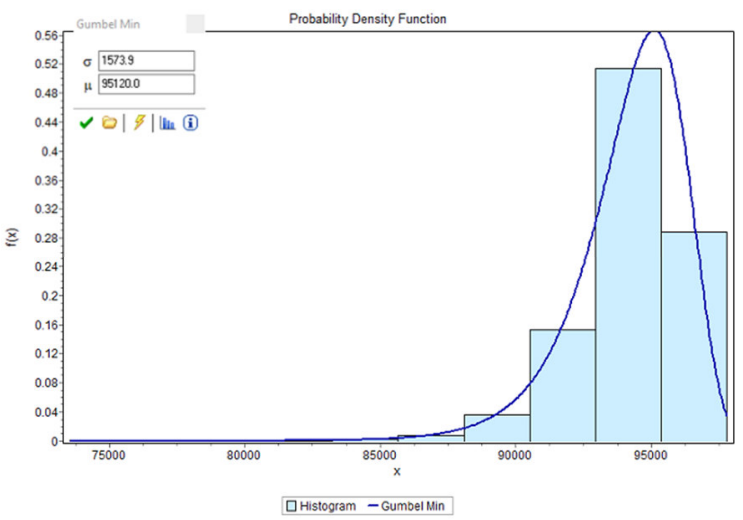

(f)

Figure 8. Probability distributions for the cost $/ \mathrm{m}^{2}$ for (a) masonry brick wall, (b) masonry block wall, (c) timberframed wall with $9.5 \mathrm{~mm}$ gypsum board, (d) timber-framed wall with $12.5 \mathrm{~mm}$ gypsum board, (e) metal-framed wall with $9.5 \mathrm{~mm}$ gypsum board, and (f) metal-framed wall with $12.5 \mathrm{~mm}$ gypsum board

A summary of the probability distributions that were fitted and their parameters is shown in the following table. These are material costs in UGX $/ \mathrm{m}^{2}$ for the different partition wall types.

Table 10. Probability distributions for the material cost to erect $1 \mathrm{~m}^{2}$ of different wall types

\begin{tabular}{|l|l|}
\hline \multicolumn{1}{|c|}{ Wall Type } & \multicolumn{1}{|c|}{ Probability distribution for $1 \mathrm{~m}^{2}$ of wall $\left(\mathrm{UGX} / \mathrm{m}^{2}\right)$} \\
\hline Masonry - brick & JohnsonSB $(-0.77791,0.74304,26574.0,20913.0)$ \\
\hline Masonry - block & Weibull $(4.8803,25479,14785)$ \\
\hline Timber framed $-9.5 \mathrm{~mm}$ gypsum board & JohnsonSB $(0.62465,0.94331,41178,40931)$ \\
\hline Timber framed $-12.5 \mathrm{~mm}$ gypsum board & JohnsonSB $(0.61856,0.92042,40157,48357)$ \\
\hline Metal framed - 9.5mm gypsum board & Gumbel $(88099.0,1596.7)$ \\
\hline Metal framed - 12.5mm gypsum board & Gumbel $(95120.0,1573.9)$ \\
\hline
\end{tabular}

\section{Cost Comparison for Different Wall Types}

It was decided that one type of wall would be used as a control and all the others would be compared to it so as to simplify the comparative analysis. The masonry brick wall was chosen as a control wall type given that it is the 
most frequently used wall type within the construction industry in Uganda. Given that costs for material for erecting a square meter of wall type are represented as probability distributions, it was deemed necessary to sample deviates from respective distributions and obtain margins of difference for a given iteration. This was repeated in several iterations (within a Monte-Carlo simulation experiment) generating a distribution of values. The Mathematica code snippet used to achieve this is summarized next.

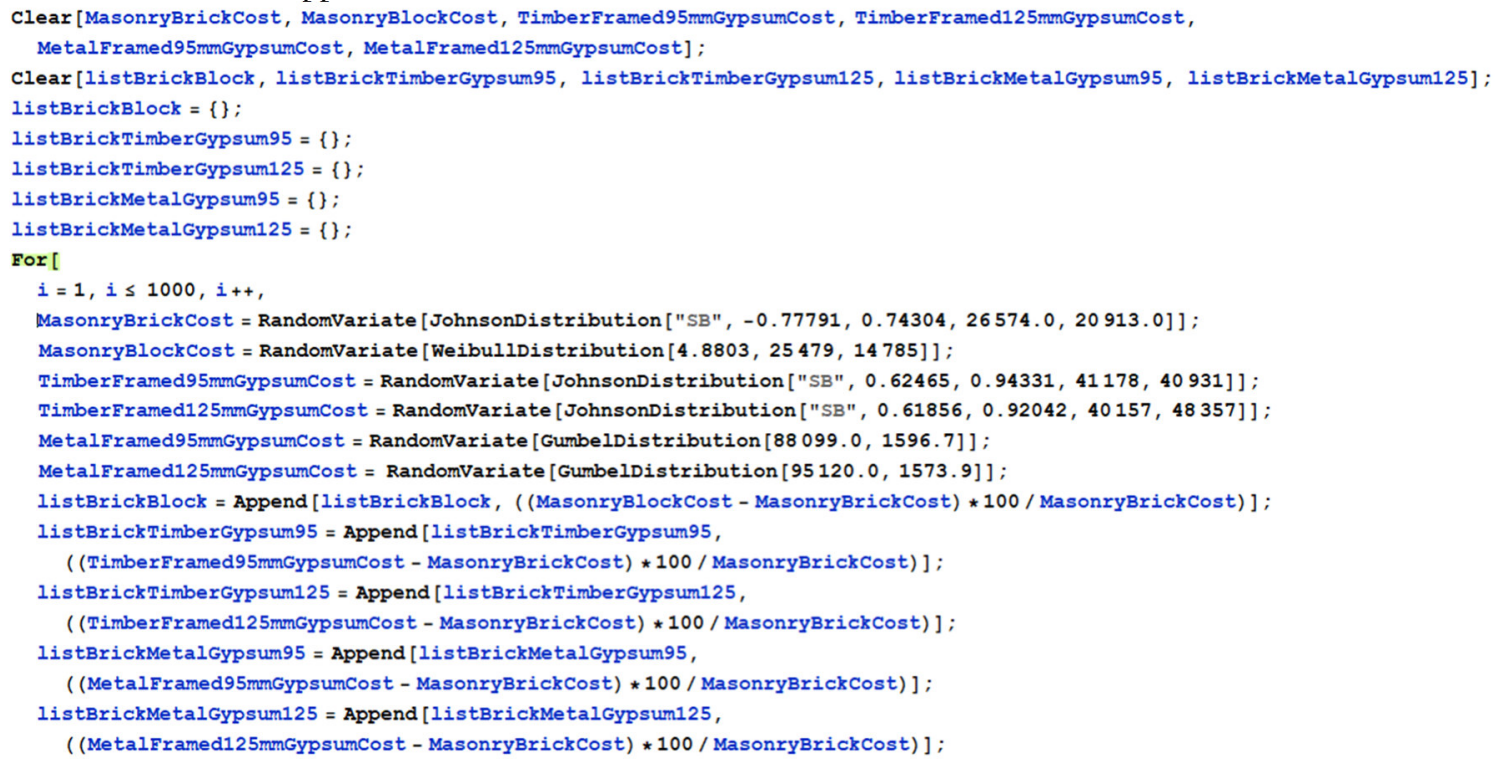

The sampling process of material cost values from probability distributions and finding the percentage differences, led to positive values for certain wall types while others led to both positive and negative values. Probability distributions were once again fitted to these percentage differences in cost using the EasyFit software. The results obtained are summarized in Table 11.

Table 11. Probability distributions for cost percentage differences between brick and other wall types

\begin{tabular}{|l|l|}
\hline \multicolumn{1}{|c|}{ Wall Type } & \multicolumn{1}{c|}{ Probability distribution material cost difference (\%) } \\
\hline Brick - block & Log-Logistic $(6.6822,67.938,-75.004)$ \\
\hline Brick - Timber framed, 9.5mm gypsum board & JohnsonSB(1.6199,1.3032,208.65,-13.085) \\
\hline Brick - Timber framed, 12.5mm gypsum board & Weibull(1.8234,62.877,-12.115) \\
\hline Brick - Metal framed, 9.5mm gypsum board & JohnsonSB(1.2814,0.78767,159.37,80.749) \\
\hline Brick - Metal framed, 12.5mm gypsum board & JohnsonSB(1.2909,0.78178,170.66,96.344) \\
\hline
\end{tabular}

Statistics were also computed for the percentage cost difference results obtained from the Monte-Carlo simulation sampling process. The values obtained are summarized in Table 12.

Table 12. Statistics for cost percentage differences between brick and other wall types

\begin{tabular}{|l|c|c|c|c|c|}
\hline \multicolumn{1}{|c|}{ Statistics } & $\begin{array}{c}\text { Brick- } \\
\text { Block }\end{array}$ & $\begin{array}{c}\text { Brick-Timber } \\
\text { Framed \& } \\
9.5 \mathrm{~mm} \\
\text { Gypsum }\end{array}$ & $\begin{array}{c}\text { Brick-Timber } \\
\text { Framed \& } \\
12.5 \mathrm{~mm} \\
\text { Gypsum }\end{array}$ & $\begin{array}{c}\text { Brick-Metal } \\
\text { Framed \& } \\
9.5 \mathrm{~mm} \text { Gypsum }\end{array}$ & $\begin{array}{c}\text { Brick-Metal } \\
\text { Framed \& } \\
12.5 \mathrm{~mm} \text { Gypsum }\end{array}$ \\
\hline Minimum & -47.56 & -9.49 & -11.32 & 72.46 & 85.24 \\
\hline Maximum & 84.58 & 140.87 & 187.06 & 216.83 & 242.25 \\
\hline Mean & -4.77 & 38.71 & 43.75 & 116.10 & 133.65 \\
\hline Standard Deviation & 18.67 & 27.77 & 31.86 & 29.62 & 31.74 \\
\hline First Quartile (Q1) & -17.88 & 17.48 & 19.91 & 93.47 & 110.00 \\
\hline Median (Q2) & -7.01 & 33.83 & 39.20 & 106.45 & 123.67 \\
\hline Third Quartile (Q3) & 5.25 & 54.48 & 63.47 & 133.09 & 150.89 \\
\hline
\end{tabular}

The statistics indicate that the material cost difference between masonry brick and masonry block is on average $-4.77 \%$ with a standard deviation of $18.67 \%$. This implies that there are times that the material cost for masonry brick is higher than that of masonry block and other it is lower hence, it could go either way. The determinants are differences in the vendor prices that are offered during material purchase. However, for the other wall types, it is clear from the results that they are more costly than the brick wall. Timber-framed wall with $9.5 \mathrm{~mm}$ gypsum board was found to be on average $38.71 \%$ more costly than masonry brick wall with a standard deviation of $27.77 \%$. Timber-framed wall with $12.5 \mathrm{~mm}$ gypsum board was found to be on average $43.75 \%$ more costly than masonry brick wall with a standard deviation of $31.86 \%$. Metal framed wall with $9.5 \mathrm{~mm}$ gypsum board was found to be on average $116.10 \%$ more costly than masonry brick wall with a standard deviation of $133.65 \%$. Metal- 
framed wall with a $12.5 \mathrm{~mm}$ gypsum board was found to be on average $133.65 \%$ more costly than the masonry brick wall with a standard deviation of $31.74 \%$.

\section{Conclusions and Recommendations}

Data was successfully collected on specifications and quantities of materials required to erect $1 \mathrm{~m}^{2}$ of each wall type. These were obtained from practitioners in the construction industry, i.e. consultants and contractors. Values obtained were verified by those obtained through a takeoff of sample standard drawing of these types of wall systems. Values that were obtained for each item in a specific wall type were very close to each other as expected and were deemed to be deterministic in nature.

Unit price data was also collected on each material item used in erecting each of the wall types. This was done through a market survey of vendors, material suppliers, and manufacturers. Variations in unit price values obtained from different sources for the same material item were evident and hence deemed to be stochastic in nature. Some of the variations arose from differences in the type material for example timber frames for pine were found to cost more than timber from eucalyptus of similar dimensions. Probability distributions were fitted to these values through an input modeling process and best-fitting probability distributions used to represent the unit price for each material item.

Costs for a unit $\mathrm{m}^{2}$ of each wall type were generated from a Monte-Carlo simulation cost-buildup experiment that utilized the quantity data and unit price probability distributions that had been fitted. These simulations generated other probability distributions for the costs per unit $\mathrm{m}^{2}$ for each wall type. Margins of difference in the cost for a unit $\mathrm{m}^{2}$ of the different wall types were obtained by sampling deviates from the distributions for the cost for a unit $\mathrm{m}^{2}$ of wall and ratios obtained. These ratios also gave rise to other probability distributions. The masonry wall type was used as the control wall type against which cost comparisons were made. Masonry walls were found to be the least expensive. The cost of erecting and finishing brick and block masonry walls were found to be very close to each other. Framed walls were found to be more expensive than masonry walls with metal-framed ones being more expensive than timber-framed walls. Framed walls analyzed excluded provisions for insulation as this was not necessary for our environment. The results explain the common trend observed in the wall types used in the construction industry in Uganda and in developed countries. Masonry walls are the predominant wall type used in the building industry in Uganda because they are the least cost. It's only executive commercial and institutional buildings that make use of framed partition walls because it makes economic sense and permits flexibility in remodeling space in the building. In developed countries, the cheaper framed walls, i.e., timber are reserved for use in residential (typically low rise) while metal frames (that are more costly), are utilized in all high rise building complexes, commercial and institutional facilities.

Besides cost, there are some other performance metrics on which the studied wall types have different scores such as weight, sound-proofing, fire resistance, etc. Literature shows that masonry walls have better soundproofing and file resisting properties than framed walls. The superior sound-proofing is attributed to a higher density of the material used in masonry walling and the fact that it is a continuous continuum. The better fire resistance of masonry walls is attributed to the fact that masonry material is less combustible than the material used to build framed walls. The higher density of masonry makes this type of wall heavier and more permanent than framed walls. It is easier to take down and shift the location of framed walls compared to the masonry wall. This is common where refurbishment and remodeling work needs to be done. These differences in performance metrics influence the choice of the type of wall to use besides cost criteria.

In construction, materials constitute a significant portion of the capital cost. It has been reported that in most cases, materials account for at least $50 \%-60 \%$ of the capital cost on construction projects. As such, this aspect (material cost) was the main focus of this study. However, in order to get a true sense of the relative cost of different types of walls, one needs to determine each of their respective capital costs. This would require the inclusion of labor, equipment, and tool costs over the material cost. It is recommended that this aspect be pursued as a next step towards extending the work done in this study. Subsequent studies could involve establishing productivity of crews and equipment used in the erection of each of these types of walls along with their hourly rates charged and this used to build-up costs for the component that involves the actual erection of the wall. The labor/equipment/tool costs together with the material costs would constitute the bare capital cost. The other cost components that would be remaining to obtain a complete whole life cycle cost of each wall type include operating and maintenance costs. It is recommended to embark on these as the last because they are extremely difficult to track and quantify and would require a lot of time.

\section{References}

Bailey, S. (2017). The key differences between blockwork and brickwork. [Online] Available: https://bsbgroup.com/blog/key-differences-between-blockwork-and-brickwork (April, 2020)

Ballou, G. (2002). Handbook for sound engineers. $3^{\text {rd }}$ ed. Boston: Focal.

Baumgart, A. \& Neuhauser, D. (2009). Franklin and Lillian Gilbreth: Scientific management in the operating room. 
Quality safety health care, Vol. 18, No. 2.

Food and Agricultural Organization of the United Nations \& Information Network on Post-Harvest Operations. (1988). A Textbook for Structural Engineering and Design. Eds. Bengtsson, L. \& Whitaker, J.

Hatzinikolas, M. \& Korany, Y. (2005). Masonry Design for Engineers and Architects. Edmonton: Canadian Masonry Publications.

Krenn, M. (2011). From scientific management to homemaking: Lillian M. Gilbreth's contributions to the development of management thought. Management \& Organizational History, Vol. 6, No. 2.

Manfred, H. (2006). Construction materials manual l. Basel: Birdhouse

United States Gypsum Company. (2015). Type X VS. Type C: Not all gypsum boards are created equal. White Paper.

Myron, F. R. (2002). Drywall: professional techniques for great results. Ed. Newtown, CT: Taunton Press.

Nardon, J. D. (1995). Bridge and Structure Estimating. Pennsylvania: McGraw-Hill Book Company.

Payne, S. C., Youngcourt, S. S. \& Watrous, K. M. (2006). Portrayals o F. W. Taylor across textbooks. Journal of management history, Vol. 12, No. 4.

Price, B. (1989). Frank and Lillian Gilbreth and the manufacture and marketing of motion study, 1908-1924. Business and economic history, Vol. 18, No. 2. 